\title{
How relevant is lumbar bone mineral density for the stability of symphyseal implants? A biomechanical cadaver study
}

\author{
Fanny Schwaabe ${ }^{1}$ Johannes Gleich ${ }^{1} \cdot$ Christoph Linhart $^{1}$ - Alexander Martin Keppler ${ }^{1} \cdot$ Matthias Woiczinski $^{1}$. \\ Christian Kammerlander ${ }^{2}$ · Axel Greiner ${ }^{1} \cdot$ Wolfgang Böcker $^{1} \cdot$ Adrian Cavalcanti Kußmaul $^{1}$ (1)
}

Received: 14 September 2021 / Accepted: 26 November 2021 / Published online: 8 December 2021

(c) The Author(s) 2021

\begin{abstract}
Purpose Osteoporotic bone tissue appears to be an important risk factor for implant loosening, compromising the stability of surgical implants. However, it is unclear whether lumbar measured bone mineral density (BMD) is of any predictive value for stability of surgical implants at the pubic symphysis. This study examines the fixation strength of cortical screws in human cadaver specimens with different BMDs.

Methods The lumbar BMD of ten human specimens was measured using quantitative computed tomography (qCT). A cutoff BMD was set at $120 \mathrm{mg} \mathrm{Ca}-\mathrm{Ha} / \mathrm{mL}$, dividing the specimens into two groups. One cortical screw was drilled into each superior pubic ramus. The screw was withdrawn in an axial direction with a steady speed and considered failed when a force decrease was detected. Required force $(\mathrm{N})$ and pull-out distance $(\mathrm{mm})$ were constantly tracked.

Results The median peak force of group 1 was $231.88 \mathrm{~N}$ and $228.08 \mathrm{~N}$ in group 2 . While BMD values differed significantly $(p<0.01)$, a comparison of peak forces between both groups showed no significant difference $(p=0.481)$.

Conclusion Higher lumbar BMD did not result in significantly higher pull-out forces at the symphysis. The high proportion of cortical bone near the symphyseal joint allows an increased contact of pubic screws and could explain sufficient fixation. This condition is not reflected by a compromised lumbar BMD in a qCT scan. Therefore, site-specific BMD measurement could improve individual fracture management.
\end{abstract}

Keywords Biomechanics $\cdot$ Fracture $\cdot$ Osteoporosis $\cdot$ Bone mineral density $\cdot$ Pull-out force $\cdot$ Osteosynthesis $\cdot$ Pubic symphysis

\section{Introduction}

Anterior plating remains the preferred surgical treatment for symphyseal disruptions [1, 2]. However, complications after fixation of symphyseal injuries are frequent and wide-ranging [2]. Besides infection and patient discomfort, implant failure is the main indication for surgical revision [3].

Fanny Schwaabe and Johannes Gleich contributed equally and share first authorship.

Adrian Cavalcanti Kußmaul

adrian.kussmaul@med.uni-muenchen.de

1 Department of Orthopaedics and Trauma Surgery, Musculoskeletal University Center Munich (MUM), University Hospital, LMU Munich, Marchioninistr. 15, 81377 Munich, Germany

2 AUVA Traumahospital Styria, Graz, Austria
Radiological signs of screw loosening are described in up to $81 \%$ of the patients, while therapeutical relevance remains controversial [3]. If loosening is associated with a loss of fracture reduction and symptomatic diastasis, surgical revision is indicated [4].

For comprehensive fracture management, all factors influencing stability of the applied osteosynthesis have to be considered [5-7]. Reduced bone mineral density (BMD) could affect stability of the osteosynthesis and prevails around the world due to demographic changes [8-12]. Significant risk factors for osteopenia and osteoporosis are increased life expectancy, immobilisation and previous fractures [13]. BMD is an important parameter in diagnostics of osteopenia and osteoporosis, allowing the evaluation of fracture risk in the elderly and enabling monitoring of an existing osteoporosis therapy $[13,14]$. It is commonly assessed via dual-energy X-ray absorptiometry (DXA) or quantitative computed tomography (qCT) at the lumbar spine [15, 
16]. Biomechanical studies presented that some implants are more likely to malfunction in models with lower bone density than in those with higher bone density [7]. Seebeck et al. concluded that cortical thickness and cancellous density have a significant effect on the retention force of screws for axial pull-out loading on human tibiae [6]. Other studies demonstrated a significant positive correlation of BMD with the insertion torques of cortical bone screws in human cadaveric femoral bones and of trabecular BMD with pullout forces at the proximal humerus [17, 18]. In contrast, Choe et al. did not find a significant correlation between lumbar measured t-scores and different regions of the femur in osteoporotic patients [11]. Similarly, Cummings et al. showed that bone density measured at the distal radius or the spine is not as accurate for assessing the risk of hip fracture than values measured at the femoral neck itself [19].

This study aims to evaluate the influence of decreased lumbar BMD, assessed via qCT, its consecutive transferability and potential predictive value for the stability of symphyseal cortical screws.

The authors hypothesize that lumbar BMD, determined via $\mathrm{qCT}$, has no significant influence on the pull-out strength of cortical screws used in symphyseal plating.

\section{Materials and methods}

Ten fresh-frozen human cadaveric anterior pelvic rings were used in this biomechanical study. Approval of the local ethics committee (approval no. 210-16) as well as of the donors' relatives was obtained prior to the investigation. The specimens included one female and nine male donors ranging from 25 to 74 years with a mean age of 60 years.

First, the bone mineral density of each pelvis was determined at the lumbar vertebrae 4 and 5 using a qCT. The mean BMD was $120.27 \mathrm{mg} \mathrm{Ca}-\mathrm{Ha} / \mathrm{mL}$ (range 63.2-171.0 mg Ca-Ha/mL, median $123.70 \mathrm{mg} \mathrm{Ca}-\mathrm{Ha} / \mathrm{mL}$ ). The specific characteristics of the specimens are provided in Table 1.

After thawing the pelvises one day in advance, they were heated in a water bath at $35{ }^{\circ} \mathrm{C}$ for 30 min immediately prior to testing to mimic body temperature. The anterior pelvic rings were then embedded in a metal cylinder filled with epoxy resin and mounted on an Instron testing machine (Instron ElectroPulsTM E10000 Linear-Torsion, Norwood, MA, USA) (Fig. 1). To ensure an exact vertical orientation of the pubic symphysis, a symphyseal plate (DePuy Synthes 3.5; four holes, dynamic compression plate, Raynham, Massachusetts, USA) was placed onto the symphyseal joint throughout the embedding and the prospective screw entry point of the medial parasymphyseal screw was marked.

Next, a cortical screw (DePuy Synthes Cortex Screw $3.5 \mathrm{~mm}, 50 \mathrm{~mm}$ ) was accordingly drilled in a 90-degree angle
Table 1 Characteristics of the specimens including age, sex and the average BMD of the pelvis specimens as determined by quantitative computed tomography (qCT)

\begin{tabular}{lllcl}
\hline Specimen & Age (years) & Sex & $\begin{array}{c}\text { Average BMD } \\
(\mathrm{mg} \mathrm{Ca}-\mathrm{Ha} / \mathrm{mL})\end{array}$ & Pull-out force (N) \\
\hline 1 & 65 & M & 64.9 & 199.59 \\
2 & 51 & F & 171.0 & 78.8 \\
3 & 60 & M & 121.6 & 133.18 \\
4 & 57 & M & 152.5 & 226.18 \\
5 & 25 & M & 151.7 & 632.8 \\
6 & 74 & M & 104.6 & 190.56 \\
7 & 67 & M & 63.2 & 264.18 \\
8 & 72 & M & 113.7 & 300.36 \\
9 & 64 & M & 125.8 & 229.99 \\
10 & 65 & M & 133.7 & 579.40 \\
\hline
\end{tabular}

to the former plate position into the superior pubic ramus parallel to the symphyseal joint (Fig. 2). This way, an exact vertical pull-out for each screw was ensured. Each screw was placed monocortically $40 \mathrm{~mm}$ into the bone using a $10 \mathrm{~mm}$ spacer.

To reduce traction forces occurring when attaching the testing machine to the screw and potentially confounding the results, a tension of $7 \pm 3 \mathrm{~N}$ was applied to every screw before starting the test protocol. The screw was then pulled out in an axial direction with a steady speed of $10 \mathrm{~mm} / \mathrm{min}$ based on a test protocol by Jöckel et al. and was considered failed when detecting a decrease in axial pull-out force and a concomitant loss of screw resistance (Fig. 3) [20]. The required force $(\mathrm{N})$ during the extraction and the dislocation distance $(\mathrm{mm})$ of the screw were permanently tracked. Similar to other studies, the pull-out strength was defined as the peak value of the force-displacement curve [6, 21] (Fig. 3).

For better data comparison, a cut-off value for bone density was set at $120 \mathrm{mg} \mathrm{Ca}-\mathrm{Ha} / \mathrm{mL}$, dividing the specimens into two groups. Accordingly, specimens with a density below this cut-off formed group $1(n=4)$, while those with higher values formed group $2(n=6)$. The cut-off at $120 \mathrm{mg}$ $\mathrm{Ca}-\mathrm{Ha} / \mathrm{mL}$ for bone density was chosen arbitrarily to ensure nearly equal sample sizes in each group. Subsequently, peak force values from both groups were compared.

Statistical analysis was performed with IBM SPSS Statistics (Windows, version 26.0, IMB Corp., Armonk, N.Y., USA). Determination of normal distribution was performed using the Kolmogorov-Smirnov, Shapiro-Wilk test as well as graphically, if needed. In case of normal distribution, homogeneity of variance was verified using Levene's test. In case of homogeneity of variance, a $t$ test was used. If variables showed heterogeneity of variance, a Welch test was carried out for comparison. Pearson correlation coefficient was used to evaluate linear correlation both between BMD and pull-out force and between BMD and age. Two tailed $p<0.05$ was considered as significant. 


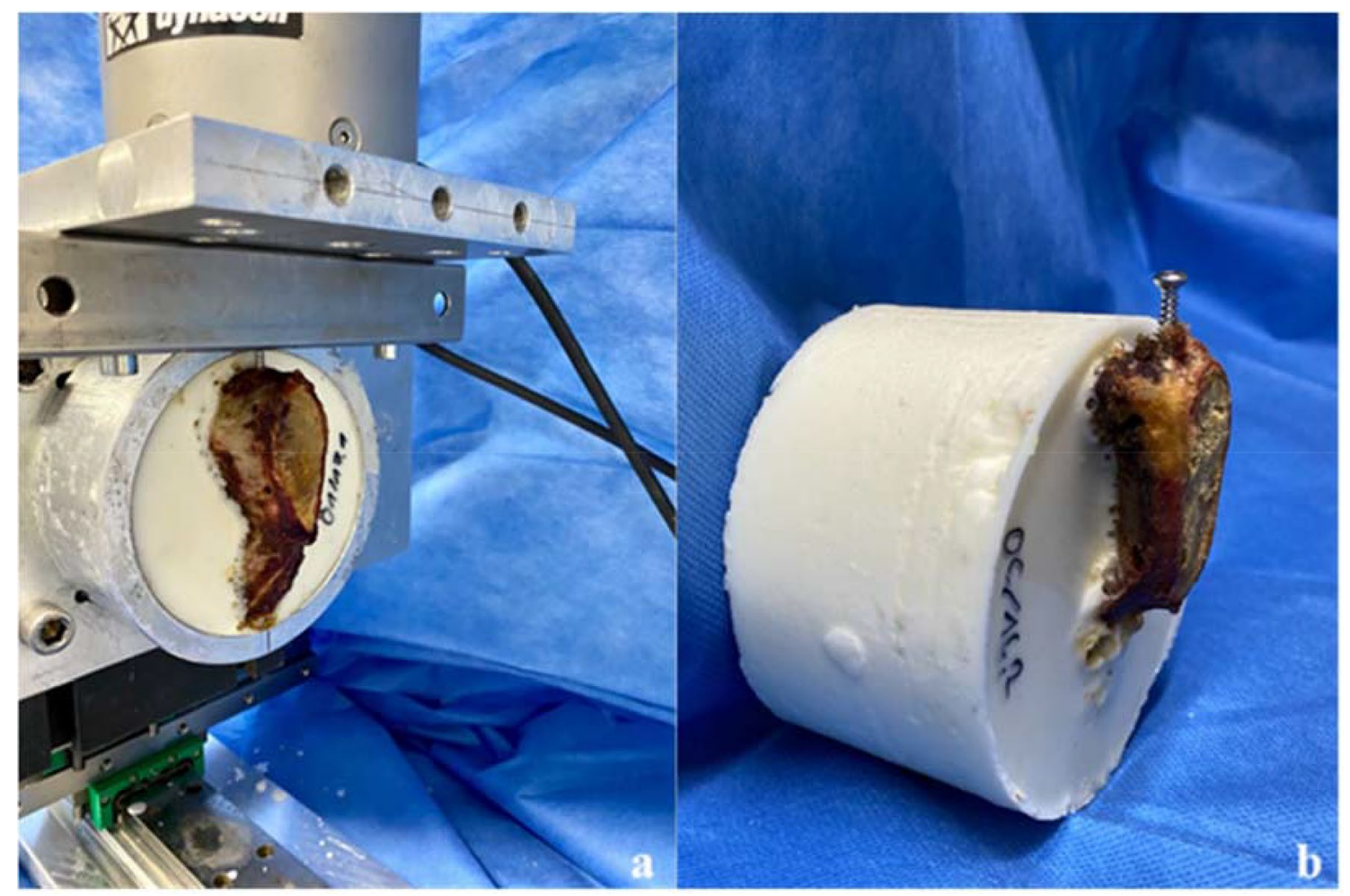

Fig. 1 Specimen embedded and mounted on the Instron testing machine during testing (a) and after screw pull-out (b)

Fig. 2 Draft of the cortical screw position from frontal (a) and medial (b)
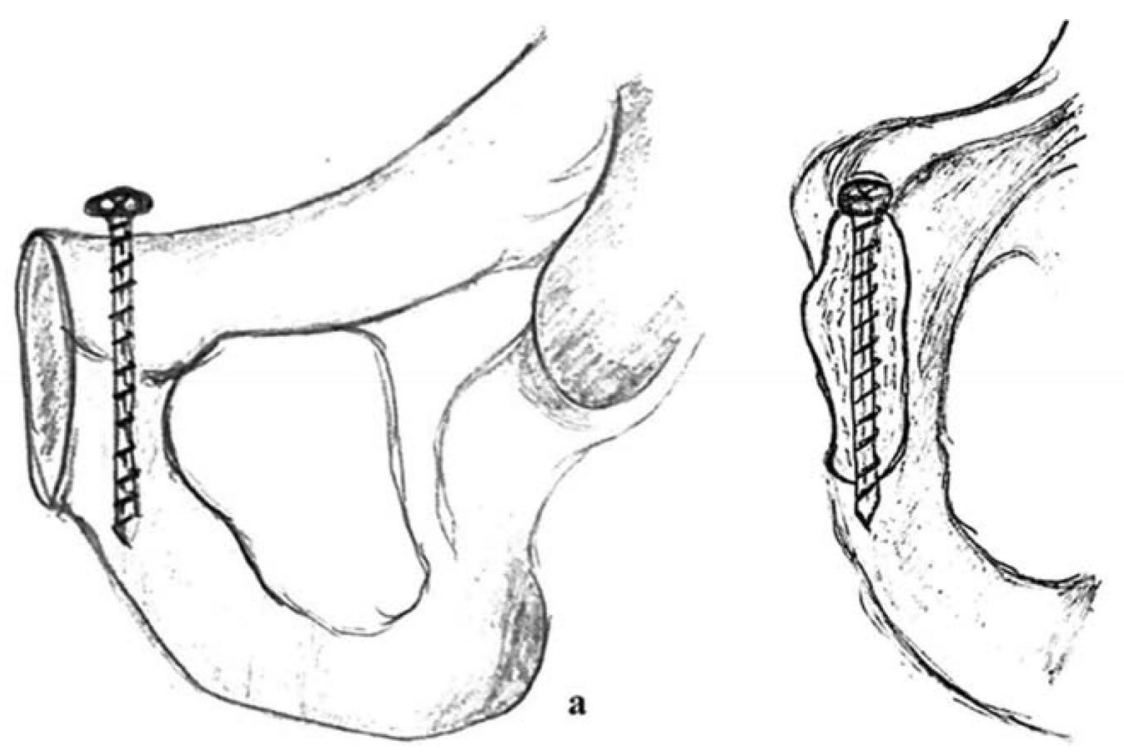

$\mathbf{b}$

\section{Results}

Group 1 (BMD $<120 \mathrm{mg} \mathrm{Ca-Ha/mL)} \mathrm{showed} \mathrm{an} \mathrm{aver-}$ age BMD of $86.60 \pm 26.31 \mathrm{mg} / \mathrm{mL}$, while group 2 (BMD $\geq 120 \mathrm{mg} \mathrm{Ca}-\mathrm{Ha} / \mathrm{mL}$ ) displayed an average BMD of
$142.72 \pm 18.92 \mathrm{mg} \mathrm{Ca}-\mathrm{Ha} / \mathrm{mL}(p<0.01)$ (Fig. 4). According to reference values in the dual-energy computed tomography (DECT) examination, bone density $<70 \mathrm{mg}$ $\mathrm{HA} / \mathrm{cm}^{3}$ can be interpreted as osteoporosis, values from 70 to $110 \mathrm{mg} \mathrm{HA} / \mathrm{cm}^{3}$ as osteopenia and values $>110 \mathrm{mg}$ 


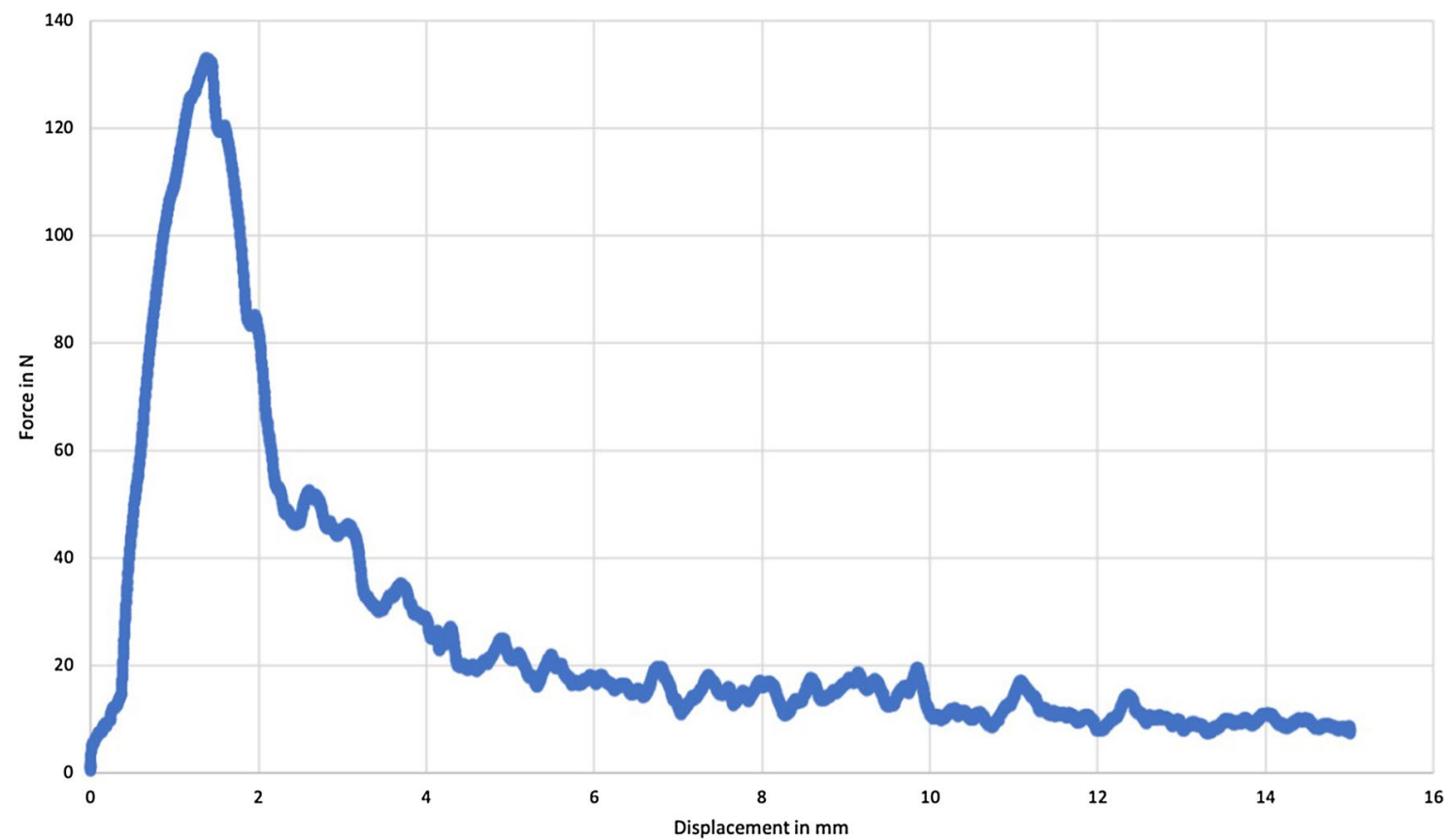

Fig. 3 Exemplary force-displacement curve (specimen 3)

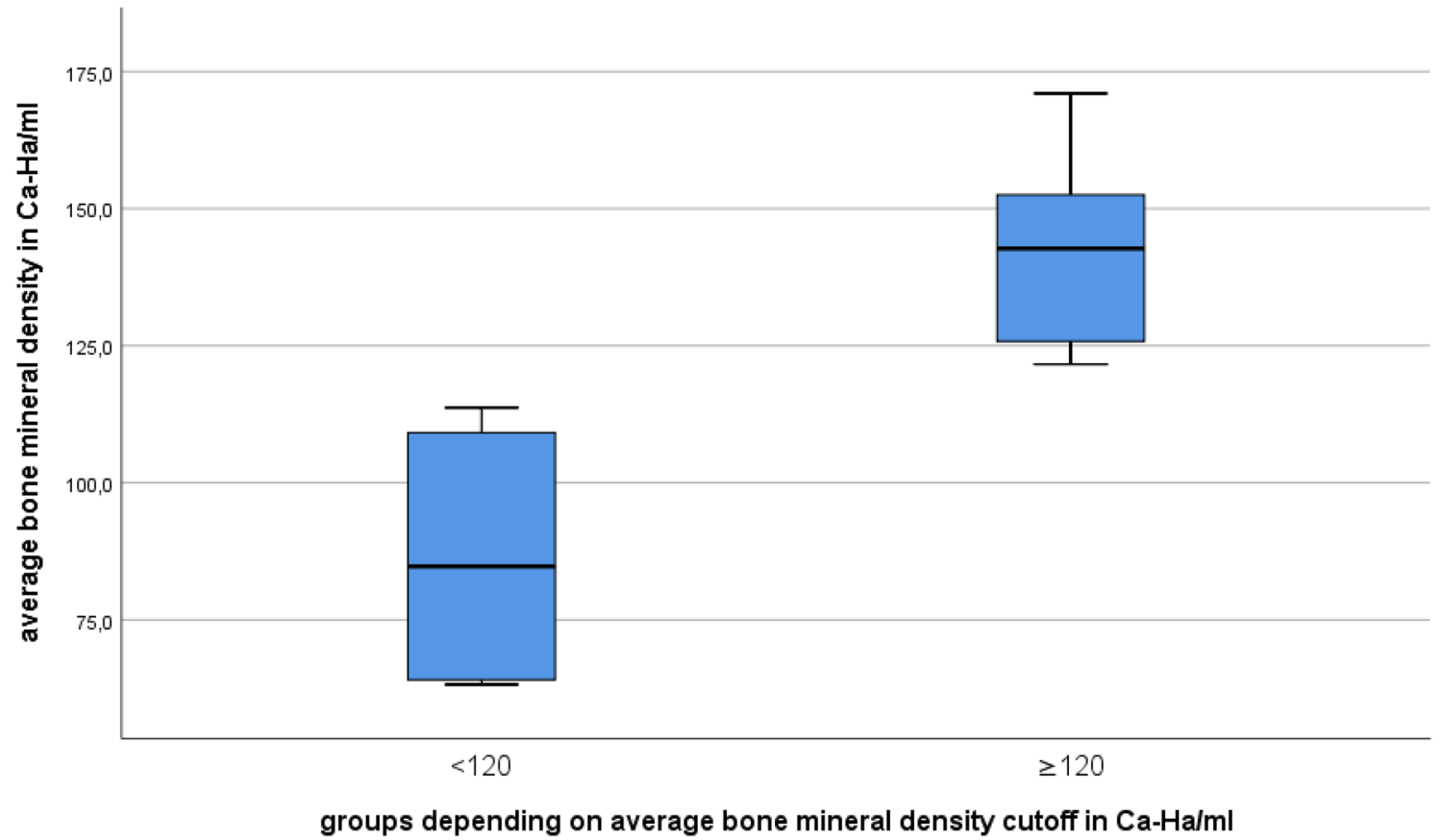

Fig. 4 Comparison of the average bone density between group 1 and 2 with respect to cut off value

$\mathrm{HA} / \mathrm{cm}^{3}$ indicate normal bone density [22]. Following this definition, two specimens showed osteoporosis (Nr. 1,7) and one osteopenia (Nr. 6).

The average pull-out peak force of group 1 was $238.67 \pm 52.60 \mathrm{~N}$, whereas group 2 had a mean pull-out peak force of $313.39 \pm 234.46 \mathrm{~N}(p=0.481)$ (Tables 1,2$)$. The median peak force of group 1 was $231.88 \mathrm{~N}$ and $228.08 \mathrm{~N}$ in group 2 (Fig. 5).

Considering the nine specimens older than 51 years while excluding the youngest one ( 25 years), average bone mineral 
Table 2 Peak forces and average bone mineral density; Group 1 (BMD < $120 \mathrm{mg} \mathrm{Ca-Ha/mL);} \mathrm{Group} 2$ (BMD $\geq 120 \mathrm{mg} \mathrm{Ca-Ha/mL)}$

\begin{tabular}{lll}
\hline & Group 1 & Group 2 \\
\hline Average BMD in mg Ca-Ha/mL & $86.60 \pm 26.31$ & $142.71 \pm 18.92$ \\
Average force peak in N & $238.67 \pm 52.6$ & $313.39 \pm 234.46$ \\
Median force in N & 231.88 & 228.08 \\
\hline
\end{tabular}

density and age showed an inverse correlation (Pearson correlation coefficient $r=-0.641)$. Bone mineral density and pull-out force showed a positive correlation $(r=0.160)$.

\section{Discussion}

The prevalence of screw loosening after anterior fixation of the pubic symphysis is high and may lead to implant failure. Therefore, possible reasons should be analysed to prevent loosening, increase stability of osteosynthesis and improve patient's outcome.

Osteoporosis compromises stability of implants at different sites (well-known at the spine or the proximal femur); thus the pubic symphysis might also be affected [8]. Osteoporosis is defined by a loss of bone mass and destruction of its microarchitecture and is associated with increased fracture risk [5, 9, 23]. To assess individual fracture risk, different ways measuring bone mineral density are available, such as a qCT scan at the lumbar spine $[15,16]$. If any correlation of BMD and pull-out strength of screws at the pubic bone could be observed, patients at risk for implant failure could be identified in advance.

In this biomechanical study no significant correlation between lumbar BMD and pull-out force and no significant difference in pull-out forces between two groups of specimens with different BMD could be observed (Fig. 4). Arbitrary categorization of tested specimens, using a BMD cut-off at $120 \mathrm{mg} \mathrm{Ca}-\mathrm{Ha} / \mathrm{mL}$, resulted in two groups with a significant difference in mean BMD $(p<0.01)$ (Fig. 4). Increased bone mineral density did not result in increased pull-out forces at pubic symphysis.

Several reasons for the restricted predictive value of lumbar determined BMD for fixation strength of screws in symphyseal osteosynthesis are possible as follows:

First, distribution of bony structures is different in vertebral and pelvic bone: while vertebral bodies mostly consist of trabecular bone, pubic bone is primarily composed of compacta [24]. This leads to increased contact surface of the pubic screw with cortical, and consequently more substantial bony structures, which may explain a higher resistance during pull-out, independent of lumbar bone quality. Furthermore, age of onset and severity of bone density loss between trabecular and cortical bone vary widely [24]. This different ageing behaviour implies that bone loss, which is already present in the spine, may not have reached the same extent in the appendicular skeleton [24]. This might explain that both groups showed almost equal median pull-out forces, even though there was a significant difference in BMD values.

Several studies have already underlined limited transferability of bone density values measured at different sites of

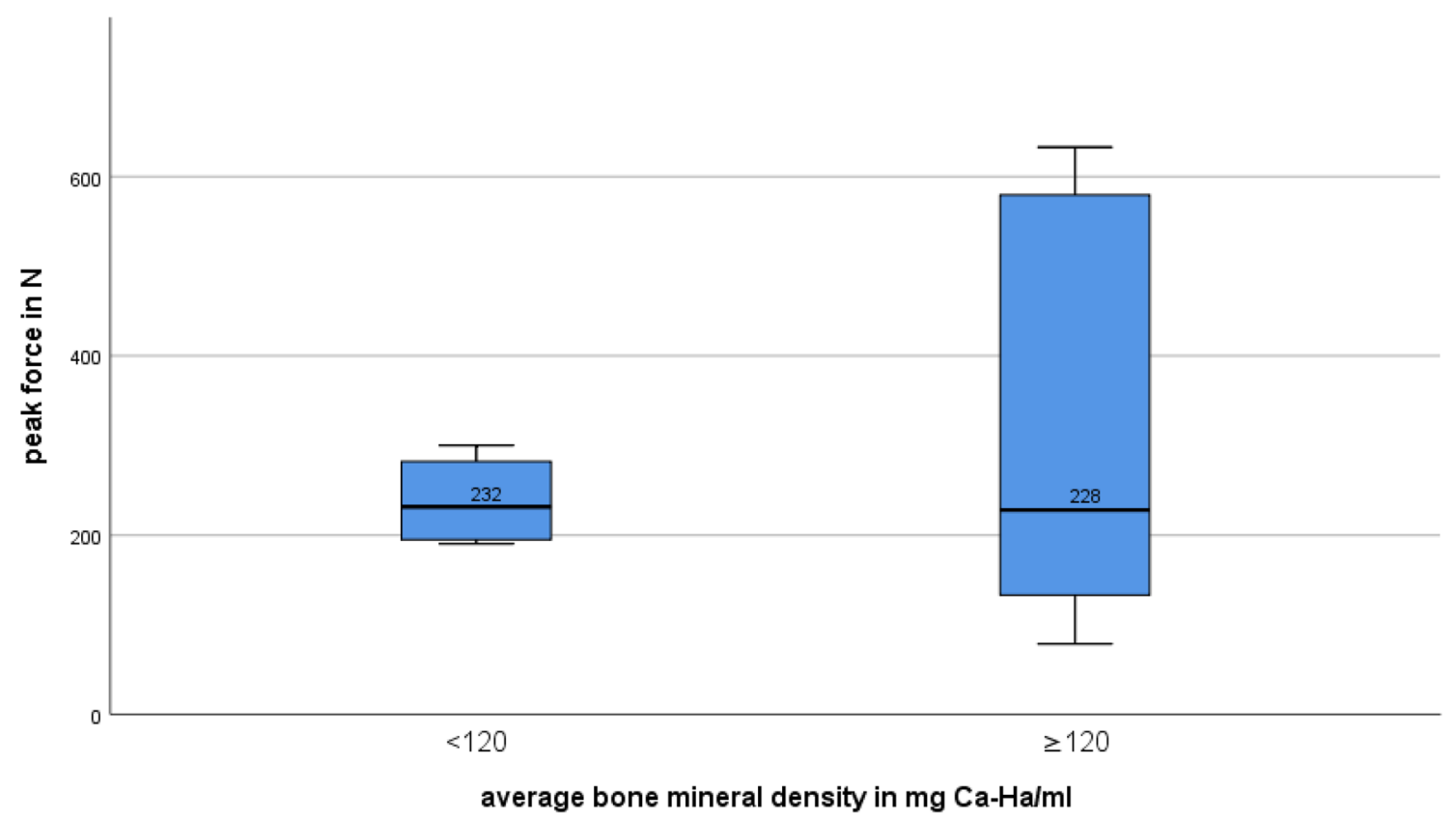

Fig. 5 Boxplot of the peak force values 
the skeleton and stated to assess BMD at the site of interest: Choe et al. observed no significant correlation between $\mathrm{T}$-scores of lumbar vertebrae and different regions of the femur in female osteoporotic patients [11]. Other groups found a positive correlation between trabecular bone mineral density of the humeral head and pull-out strength at the same site; also BMD measured at the femoral neck was more accurate for assessing the risk of hip fracture than density values gained at the radius or spine and in-situ DXA at the same skeletal spot was more likely to be related to fracture loads than at remote sites [18, 19, 24]. Bredow et al. indicated a potential benefit of preoperative bone density determination using a CT scan as a decisional aid for possible extension of surgical techniques (e.g. cement augmentation) to prevent screw loosening [25]. Also, preoperative assessment of local cancellous bone density has been described as feasible aid in the treatment of proximal femur fractures [26].

Second, bone density loss due to osteoporosis does not affect the whole organism equally [27]. Predisposing sites include bones rich of spongiosa, like the axial skeleton (vertebral bodies), the femoral neck or distal radius [23, 28]. This assumption is strengthened by a recent study, concluding that a decrease in BMD due to osteoporosis differs in time and severity at various sites of the skeleton [29]. In the present study, a decrease of average BMD with increasing donors age was observed, underlining the representativity of the specimens [29, 30]. Excluding specimen Nr. 5, there was a significant inverse correlation, which indicates a large effect size [31].

Finally, and with regard to the clinical relevance of this study, it is essential to keep in mind that compromised bone quality is only one risk factor for implant failure: symphyseal plating almost completely eliminates the physiological range of motion of the symphyseal joint (up to $2 \mathrm{~mm}$ ), resulting in an iatrogenic arthrodesis and consequently increasing the rate of implant failure [32]. Therefore, further options to improve the stability of screws for the treatment of symphyseal injuries should be explored. For example, an additional cement augmentation might increase fixation strength and reduce implant failure. This concept has already been successfully implemented in a study by Suero et al. at the posterior pelvic ring: here, a single augmented screw achieved comparable stability to a non-augmented double-screw technique [33]. Weiser et al. demonstrated a significant increase in fatigue strength of cement augmented screws in osteoporotic vertebrae $[34,35]$.

Another, potentially biomechanically superior, option could be the insertion of minimally invasive Tape-Suture constructs: these constructs have demonstrated sufficient biomechanical stability while allowing the above-mentioned micromovements of the pubic symphysis as shown by previous studies of our group [36].
Overall, this study demonstrates the importance of sitespecific densitometry regarding the corresponding implant stability and highlights the relevance of the inclusion of diverse manifestations of osteoporosis and osteopenia in the therapeutical concept.

The main limitation of this study is a relatively small sample size and an underrepresentation of osteopenic and osteoporotic BMD. Also, there is an uneven representation of male and female specimens as well as ethnicities. The opportunity to test human cadaveric specimens, however, is a great privilege and entails a very high moral obligation towards the donors. It would be unethical to reject samples to achieve an ideal ratio of osteoporotic and non-osteoporotic bone or other characteristics. The cut off value to create approximately equal sample sizes and enable better comparison was set arbitrarily and not after defined criteria, which is reasonable regarding the ethical standards mentioned above.

Another limitation was the use of identical screw lengths in all pelvises (DePuy Synthes Cortex Screw $3.5 \mathrm{~mm}$, $50 \mathrm{~mm}$ ) and the monocortical screw positioning. In a clinical setting, an individual screw length would be measured prior to insertion and a bicortical fixation attempted. This approach would have resulted in decreased comparability as the individual variation in screw length necessary to achieve bicortical screw positioning would have led to a variation in fixation strength due to the differences in thread pitches.

Yet, potential confounding variables were discussed with the biomechanical engineers prior to this study: consequently, monortical and axial screw alignment of a single symphyseal screw, identical screw length and vertical screw pull-out were chosen to minimize confounding variables, to achieve standardization of the experimental set-up and to consequently maximize comparability of the data.

\section{Conclusion}

In this biomechanical study, we were able to demonstrate that bone mineral density measured at the lumbar spine with a qCT does not allow sufficient conclusion about the fixation strength of cortical screws at the pubic symphysis. Site-specific performed densitometry should be evaluated in further studies to potentially draw conclusions for subsequent implant stability.

Also, the authors underline the importance of the inclusion of profound knowledge about the diverse manifestations of osteoporosis and osteopenia into the surgical concept.

Supplementary Information The online version contains supplementary material available at https://doi.org/10.1007/s00068-021-01850-6. 
Author contributions Study conception and design: ACK, FS, AG, WB, CK. Material preparation, experimental testing, data collection and analysis: FS, JG, ACK, MW. First draft of the manuscript: FS, JG, ACK. Review of the manuscript: JG, AK, AG, CL. Implementation of improvement: ACK, FS, JG.

Funding Open Access funding enabled and organized by Projekt DEAL. Adrian Cavalcanti Kußmaul received financial support from the WiFoMed grant (Nr: 80946025) of the Ludwig-Maximilians-University Munich. All other authors have no relevant financial or nonfinancial interests to disclose.

Availability of data and material All data is available upon request.

\section{Declarations}

Conflict of interest Adrian Cavalcanti Kußmaul received financial support from the WiFoMed grant of the Ludwig-Maximilians-University Munich. All other authors have no conflict of interest.

Ethics approval This study was performed in line with the principles of the Declaration of Helsinki. The approval of the ethics committee was obtained prior to the experiment (EA 210-16).

Consent to participate The relatives of the donors gave their consent prior to collection of the specimens.

Consent for publication All authors read and approved the final manuscript.

Open Access This article is licensed under a Creative Commons Attribution 4.0 International License, which permits use, sharing, adaptation, distribution and reproduction in any medium or format, as long as you give appropriate credit to the original author(s) and the source, provide a link to the Creative Commons licence, and indicate if changes were made. The images or other third party material in this article are included in the article's Creative Commons licence, unless indicated otherwise in a credit line to the material. If material is not included in the article's Creative Commons licence and your intended use is not permitted by statutory regulation or exceeds the permitted use, you will need to obtain permission directly from the copyright holder. To view a copy of this licence, visit http://creativecommons.org/licenses/by/4.0/.

\section{References}

1. Godinsky RJ, Vrabec GA, Guseila LM, et al. Biomechanical comparison of locked versus non-locked symphyseal plating of unstable pelvic ring injuries. Eur J Trauma Emerg Surg. 2018;44:179_ 84. https://doi.org/10.1007/s00068-016-0661-x.

2. Eastman JG, Krieg JC, Routt MLC. Early failure of symphysis pubis plating. Injury. 2016;47:1707-12. https://doi.org/10.1016/j. injury.2016.05.019.

3. Jordan MC, Jäckle V, Scheidt S, et al. Outcome after plate stabilization of symphyseal diastasis. Unfallchirurg. 2020. https://doi. org/10.1007/s00113-020-00804-8.

4. Putnis SE, Pearce R, Wali UJ, et al. Open reduction and internal fixation of a traumatic diastasis of the pubic symphysis: oneyear radiological and functional outcomes. J Bone Joint Surg Br. 2011;93:78-84. https://doi.org/10.1302/0301-620X.93B1.23941.
5. Augat $\mathrm{P}$, Bühren V. Modern implant design for the osteosynthesis of osteoporotic bone fractures. Orthopade. 2010;39:397-406. https://doi.org/10.1007/s00132-009-1572-x.

6. Seebeck J, Goldhahn J, Städele H, et al. Effect of cortical thickness and cancellous bone density on the holding strength of internal fixator screws. J Orthop Res. 2004;22:1237-42. https://doi.org/ 10.1016/j.orthres.2004.04.001.

7. Goldhahn J, Suhm N, Goldhahn S, et al. Influence of osteoporosis on fracture fixation-a systematic literature review. Osteoporos Int. 2008;19:761-72. https://doi.org/10.1007/s00198-007-0515-9.

8. Pientka L. Hip fractures (osteoporosis) and geriatric rehabilitation. Bundesgesundheitsblatt-Gesundheitsforsch-Gesundheitsschutz. 2004;47:547-53. https://doi.org/10.1007/s00103-004-0839-y.

9. Maus U, Böcker W, Schultz K, et al. Importance of osteoporosisrelated fractures for patients. Unfallchirurg. 2019;122:750-4. https://doi.org/10.1007/s00113-019-00708-2.

10. Hesse E, Böcker W, Kammerlander C, et al. Establishment of fracture liaison services in Germany. Unfallchirurg. 2019;122:766-70. https://doi.org/10.1007/s00113-019-00705-5.

11. Choe HS, Lee JH, Min DK, Shin SH. Comparison of vertebral and femoral bone mineral density in adult females. J Phys Ther Sci. 2016;28:1928-31. https://doi.org/10.1589/jpts.28.1928.

12. Minne HW, Pfeifer M, Begerow B, Pollähne W. Osteoporose. Orthopade. 2002;31:681-99. https://doi.org/10.1007/ s00132-002-0348-3.

13. Jakob F, Seefried L, Schwab M. Age and osteoporosis. Effects of aging on osteoporosis, the diagnostics and therapy. Internist. 2014;55:755-61. https://doi.org/10.1007/s00108-014-3468-z.

14. Blake GM, Fogelman I. Monitoring treatment for osteoporosis by using bone densitometry. Semin Nucl Med. 2001;31:212-22. https://doi.org/10.1053/snuc.2001.23528.

15. Heuchemer L, Emmert D, Bender T, et al. Pain management in osteoporosis. Orthopade. 2020;49:363-76. https://doi.org/10. 1007/s00132-020-03898-5.

16. Scheyerer MJ, Ullrich B, Osterhoff G, et al. Hounsfield units as a measure of bone density-applications in spine surgery. Unfallchirurg. 2019;122:654-61.

17. Koistinen A, Santavirta SS, Kröger H, Lappalainen R. Effect of bone mineral density and amorphous diamond coatings on insertion torque of bone screws. Biomaterials. 2005;26:5687-94. https://doi.org/10.1016/j.biomaterials.2005.02.003.

18. Tingart MJ, Lehtinen J, Zurakowski D, et al. Proximal humeral fractures: Regional differences in bone mineral density of the humeral head affect the fixation strength of cancellous screws. J Shoulder Elb Surg. 2006;15:620-4. https://doi.org/10.1016/j.jse. 2005.09.007.

19. Cummings SR, Browner W, Cummings SR, et al. Bone density at various sites for prediction of hip fractures. Lancet. 1993;341:725. https://doi.org/10.1016/0140-6736(93)92555-8.

20. Jöckel JA, Strehl R, Gotzen L. Biomechanical evaluation of biointegrable suture anchors composed of bovine compact bone in a pull-to-failure test in porcine tibial head specimens. Z Orthop Ihre Grenzgeb. 2006;144:626-31. https://doi.org/10. 1055/s-2006-942236.

21. Shih KS, Hou SM, Lin SC. Theoretical prediction of pullout strengths for dental and orthopaedic screws with conical profile and buttress threads. Comput Methods Programs Biomed. 2017;152:159-64. https://doi.org/10.1016/j.cmpb.2017.08.004.

22. Felsenberg D, Gowin W. Bone densitometry by dual energy methods. Radiologe. 1999;39:186-93. https://doi.org/10.1007/s0011 70050495.

23. Chao EYS, Inoue N, Koo TKK, Kim YH. Biomechanical considerations of fracture treatment and bone quality maintenance in elderly patients and patients with osteoporosis. Clin Orthop Relat Res. 2004. https://doi.org/10.1097/01.blo.0000132263. 14046.0c. 
24. Riggs BL, Wahner HW, Dunn WL, et al. Differential changes in bone mineral density of the appendicular and axial skeleton with aging. Relationship to spinal osteoporosis. J Clin Invest. 1981;67:328-35. https://doi.org/10.1172/JCI110039.

25. Bredow J, Boese CK, Werner CML, et al. Predictive validity of preoperative CT scans and the risk of pedicle screw loosening in spinal surgery. Arch Orthop Trauma Surg. 2016;136:1063-7. https://doi.org/10.1007/s00402-016-2487-8.

26. Erhart S, Zegg M, Kralinger F, et al. Fast and easy preoperative estimation of cancellous bone mineral density in patients with proximal femur fractures. Arch Orthop Trauma Surg. 2015;135:1683-9. https://doi.org/10.1007/s00402-015-2340-5.

27. Eckstein F, Lochmüller EM, Lill CA, et al. Bone strength at clinically relevant sites displays substantial heterogeneity and is best predicted from site-specific bone densitometry. J Bone Miner Res. 2002;17:162-71. https://doi.org/10.1359/jbmr.2002.17.1.162.

28. Osteoporose K, Mineralstoffwechsel J, Stichwortsuche A. Homepage: mineralstoffwechsel online-Datenbank mit. Präv Ther. 2007;14:185-97.

29. Lee C, Lee JH, Han SS, et al. Site-specific and time-course changes of postmenopausal osteoporosis in rat mandible: comparative study with femur. Sci Rep. 2019;9:1-9. https://doi.org/ 10.1038/s41598-019-50554-w.

30. Hesse E, Neuerburg C, Kammerlander C, et al. Influence of specific osteoporosis drugs on fracture healing. Unfallchirurg. 2019;122:506-11. https://doi.org/10.1007/s00113-019-0669-x.
31. Cohen J. Statistical power analysis for the behavioral sciences. Cambridge: Academic press; 2013.

32. Walheim G, Olerud S, Ribbe T. Mobility of the pubic symphysis: measurements by an electromechanical method. Acta Orthop. 1984;55:203-8. https://doi.org/10.3109/17453678408992338.

33. Suero EM, Greiner A, Becker CA, et al. Biomechanical stability of sacroiliac screw osteosynthesis with and without cement augmentation. Injury. 2020. https://doi.org/10.1016/j.injury.2020.01.043.

34. Weiser L, Sehmisch S, Lehmann W, Viezens L. Techniques to increase pedicle screw stability in osteoporotic vertebrae. Oper Orthop Traumatol. 2019;31:284-92. https://doi.org/10.1007/ s00064-019-0608-6.

35. Weiser L, Sehmisch S, Viezens L, Lehmann W. Intraoperative revision of initially loosened pedicle screws. Oper Orthop Traumatol. 2019;31:293-300. https://doi.org/10.1007/ s00064-019-0611-y.

36. Cavalcanti Kußmaul A, Schwaabe F, Kistler M, Gennen C, Andreß S, Becker CA, Böcker W, Greiner A. Novel minimally invasive tape suture osteosynthesis for instabilities of the pubic symphysis: a biomechanical study. Arch Orthop Trauma Surg. 2021. https:// doi.org/10.1007/s00402-021-03968-z. 